\title{
Differentiation among targets in social perception as a function of response hierarchy
}

Judges high or low in number of words descriptive of others which were emitted in continuous association were asked to predict the responses of two ficticious targets. Half the judges were presented targets contrived to be similar to one another, half dissimilar targets. The presence of quantitatively more descriptive responses in one's hierarchy facilitated differentiation among social targets when real differences existed. The usefulness of response hierarchies in investigating social perception behavior was discussed.

Judges' response tendencies have been shown to be determinants of social perception responses, both on a theoretical (Cronbach, 1955; Jones \& Thibaut, 1958; Levy, 1963) and an empirical level (Kaplan, 1967a, b). One line of research has attempted to relate ability to differentiate among stimulus persons (targets) to personality of the judge, and has generally met with lack of success (Shrauger \& Altrocchi, 1964). Findings are reported, however, by Bieri et al (1966), which suggest that cognitive complexity, as measured by the number of dimensions people use in describing others on the Kelly Role Construct Repertory Test, is positively related to tendencies to make distinctions among targets. In the present study, it was hypothesized that ability to differentiate among targets would be directly related to number of responses available for describing others in the judge's hierarchy. The judge who typically uses a wider range of responses in describing others will have a wider latitude for responding with different responses to real differences among others.

Method

Subjects. Response hierarchies were elicited by a continuous association technique similar to that used by Garskof \& Houston (1963) in measuring response hierarchies in word association. Females enrolled in an introductory psychology course were asked to list all the words they could think of in a 7 min span which could be used to describe others (omitting physical terms). Reliability over time (six weeks) of number of words emitted was .75. Females having more than the median number of words were designated as high hierarchy range (HH), those with less, low hierarchy (LH). Seventy-six Ss from each group were randomly chosen to participate in the study. The mean number of words emitted by $\mathrm{HH}$ Ss was 64.0 , by LH, 35.4.

Targets. Four sets of six statements each were constructed, each statement purportedly representing the opinions of an acquaintance toward one of four dif- ferent targets. One pair of sets described targets similar. in statement content to one another; the other pair, dissimilar. The statements in the similar pair were constructed by paraphrasing descriptions of high of low scorers ${ }^{2}$ on six of the Need Scales provided with the Edwards Personal Preference Schedule (Edwards, 1959) and the Adjective Check List (Gough \& Heilbrun, 1965). Parallel sets of descriptions were constructed for the two targets in the similar condition. For the dissimilar condition (DC), one of the targets was described in terms identical to those in the similar condition (SC), the other in statements describing people earning opposite scores on the same scales.

Procedure. Half the Ss in each hierarchy group predicted the behavior of the DC target, half the SC targets. Ss were presented the written statements for one target, told that they were elicited from acquaintances of his, and then asked to predict which adjectives the target endorsed as true of himself on the Adjective Check List (ACL). The process was repeated for the second target, order of presentation of targets within pairs being counterbalanced. To facilitate comparisons, all Ss were asked to check exactly 100 adjectives, approximating the average number of adjectives checked normatively. The design was thus a 2 by 2 factorial, with 2 levels of judge hierarchy, and 2 levels of target similarity.

\section{Results and Discussion}

The response measure consisted of number of differences in endorsements of adjectives within the pair of targets in each condition. Mean differences for the HH-DC, LH-DC, HH-SC, and LH-SC groups were, respectively, $81.4,69.8,39.6$, and 38.1. Analysis of variance disclosed a significant effect for hierarchy $(F=9.03, d f=1 / 148, p<.005)$, similarity $(F=284.3$, $\mathrm{df}=1 / 148, p<.001$ ), and hierarchy by simllarity interaction $(F=5.24, \mathrm{df}=1 / 148, \mathrm{p}<.025)$. HH tended to predict more differences between their targets, but this was due to the dissimilar condition, the differences between the hierarchy groups being negligible when targets were similar. All Ss predicted more differences between targets when they were dissimilar than when similar. The finding of no difference between hierarchy groups with similar targets contraindicates the possibility that HH had higher differentiation scores than LH with dissimilar targets due to greater response variability. 
The question arises as to why responses varied almost $40 \%$ from one similar target to another. It is likely that this may be attributed to unreliability of the ACL as well as variability inherent in predicting the behavior of others. An independent sample of 18 Ss was asked to predict the responses of a third pair of targets having identical statements derived from a new set of six Need Scale dimensions. ${ }^{3}$ Order of presentation of statements differed between the two targets. Differentiation scores for the identical condition closely approximated those of the similar condition $(\bar{X}=36.4)$. Ss with identical targets all reported afterwards that they were aware both targets were identical.

The presence of quantitatively more descriptive responses in one's hierarchy was found to facilitate differentiation among social targets. Ability to differentiate may therefore be considered, at least in part, a function of associative or learning variables. The usefulness of response hierarchy as a predictor might profitably be extended to social perception responses in general. For example, research is currently underway examining individual differences in attribution of traits as a function of differences in saliency of given response tendencies in the hierarchy associated with the general task of describing others.

While Bieri and his co-workers (1966) have found their measure of cognitive complexity to be a predictor of differentiation tendencies, the continuous association method of assessing response tendencies may possess a number of advantages. First, it is a simpler and more direct manner of eliciting tendencies in describing others. Second, one need not invoke the presence of cognitive structures but instead can relate individual differences in social perception to associational, or habit variables, which are more amenable to experimental manipulation. Third, the cognitive complexity concept has little explanatory appli- cation beyond differentiation. Response hierarchies, as measured by the continuous association technique, can be studied in relation to specified trait attribution tendencies, contribution to accuracy, relevance for a given target, and social perception responses in general. It is advanced that the response hierarchy approach may be a fruitful way of investigating social perception behavior.

\section{References}

BIERI, J., ATKINS, A. L., BRIAR, S., LEAMAN, ROBIN L., MILLER, H., \& TRIPOLDI, T. Clinical and Social Judgment. New York: Wiley, 1966.

CRONBACH, L. J. Processes affecting scores on "understanding of others" and "assumed similarity" Psychol. Bull; 1955, 52, 177-194.

EDWARDS, A. L. Manual for the Edwards Personal Preference Schedule. New York: Psychological Corp., 1959.

GARSKOF, B. G., \& HOUSTON, J. P. Measurement of verbal relatedness: an idiographic approach. Psychol. Rev., 1963, 70, 277-288.

GOUGH, H. G., \& HEILBRUN, A. G., JR. Joint Manual for the Adjective Check List and the Need Scales for the ACL. Palo Alto: Consulting Psychologists Press, 1965.

JONES, E. E., \& THIBAUT, J. W. Interaction goals as bases of inference in interpersonal perception. In Tagiuri, R., and Petrullo, L. (Eds.), Person Perception and Interpersonal Behavior. Stanford: Stanford Univer. Press, 1958, 151-178.

KAPLAN, M. F. Information elicitation and behavior prediction by repressors, sensitizers, and neutrals. Paper read at Midwest. Psychol. Assoc., May, 1967a.

KAPLAN, M. F. Repression-Sensitization and prediction of self-descriptive behavior: response vs situational cue variables. J. abnorm. soc. Psychol., 1967b, 72, 354-361.

LEVY, L. H. Reversal response sets and the nature of person perception. J. abnorm. soc. Psychol., 1963, 67, 392-396.

SHRAUGER, S., \& ALTROCCHI, J. The personality of the perceiver as a factor in Person Perception. Psychol Bull., 1964, 62, 289-308.

Notes

1. This research was supported by NIU Deans Fund Grant No. 54006-35.

2. High score earned on Favorability, Affiliation, Achievement, Dominance; Low score on Abasement, Unfavorability.

3. High score earned on Deference, Exhibition, Change, Heterosexuality: Low score on Endurance, Intraception. 